\title{
THE COMPARISON OF ELEVATED LEVELS OF EBV IMMUNOGLOBULIN A EARLY ANTIGEN BETWEEN NASOPHARYNGEAL CARCINOMAWHO TYPE 3 WITH MALIGNANT NON-HODGKIN LYMPHOMA
}

\author{
Ariel Anugrahani ${ }^{*}$, Bogi Soeseno ${ }^{1}$, Yussy Afriani Dewi ${ }^{1}$, Nur Akbar Aroean ${ }^{1}$ \\ ${ }^{1}$ Department of Otorhinolaryngology Head and Neck Surgery Padjadjaran University, Hasan Sadikin General Hospital Bandung
}

\section{Abstract}

Introduction: Epstein Barr Virus (EBV) replicate in the epithelial cells and becomes latent in lymphocytes B. This virus is also associated with NPC, NHL, infectious mononucleosis and Burkitt's lymphoma. The expression product of EBV acute infections can interact with genes in the epithelial cells to start the molecular level that leads to malignancy so that an increase in levels of IgA antibodies EA can indicate high levels of EBV infection. Objective: Comparing the level of IgA EA antibody for EBV between NPC WHO type III and NHL.

Method: Observational comparative analytic method with cross-sectional study design. The subject of this study are 16 NPC patients and 16 NHL patients, consists of 9 males and 7 females. Numeric data of IgA EA calculated by Mann Whitney and the categoric data is calculated by Kolmogorov Smirnov. The examination of IgA EA level in EBV using ELISA method, with p-value $<0.05$

Result: This study reveals that there were increasing IgA EA levels in NPC patients $(3.71 \pm 2.36)$ compared to NHL $(0.27 \pm 0.20)$. There is a difference value of IgA EA in study groups both numerical and categorical.

Conclusion: The level of IgA EA EBV antibody in NPC is higher than NHL.
\end{abstract}

\section{Article Info}

Keywords:

IgA EA, NPC, NHL, EBV

\section{*Corresponding author}

Address: Jalan Professor Eyckman No.38 Bandung 40161, Indonesia

e-mail: dr.arielanugrahani@gmail.com

\section{INTRODUCTION}

Nasopharyngeal Carcinoma (NPC) is an epithelial neoplasm arising from the fossa of Rosenmuller of the postnasal space [1]. Epstein-Barr virus (EBV) or human herpesvirus 4 is ubiquitous, and about $90 \%$ of adults throughout the world have antibodies against it. Acute infection is usually asymptomatic in immunocompetent children and manifests itself as mononucleosis in $30 \%-50 \%$ of immunocompetent adolescents and adults $[2,3]$. This is a rare tumor in the most part of the world, but it occurs endemically in Southern China, Hong Kong, Singapore and some other part of Southeast Asia with high incidence [1,2]. Epstein-Barr Virus (EBV) has long been implicated as an important etiological factor of NPC with histological evidence, indicating the consistent presence of the viral DNA and proteins in malignant tissue. The EBV is clonally present in virtually $100 \%$ of undifferentiated NPC cases [3]. Epidemiology of NPC is unique, this disease is a malignancy that is rarely found in most parts of the world; endemic in South China (25 per 100,000 populations per year in Guangzhou), Hong Kong, Singapore, and parts of Southeast Asia. In Europe, the incidence of the disease is less than 1 per 100,000 population per year [3]. The incidence of NPC in Indonesia reaches 6.7 per 100,000 population per year with the highest incidence of $4-5$ decades and the ratio between men and women is 2-3:1.4. In Indonesia NPC ranks fourth in all malignancies after cervical, breast and skin cancer. The incidence increased in the last decade II and reached its peak at the age of 40-50 years and was ranked first in the ORL-HNS Health Sciences field which reached $28 \%$ of all cases of head and neck carcinoma. The prevalence of NPC in the Department of ORL-HNS Hasan Sadikin Hospital Bandung during the period of 2010-2014 was 39.4\% [4].

Classification of NPC is histologically, namely keratinized squamous cell carcinoma (WHO type I), non-keratinized squamous cell carcinoma (WHO type II), and undifferentiated carcinoma (WHO type III). Factors that play a role in the pathogenesis of NPC include EBV, genetic susceptibility, and risk factors from the environment. Genetic susceptibility such as HLAA2 and HLA-BSin2 loci act as predisposing factors. Some environmental factors that are thought to be related to NPC are diet, exposure to chemicals in the workplace and tobacco [5].
Especially in immunocompromised patients, EBV is associated with various lymphoproliferative disorders and some neoplastic diseases, including Burkitt's lymphoma and nasopharyngeal carcinoma. Like other herpes viruses, EBV has a productive lytic cycle and a latent phase. B lymphocytes are infected after the viral envelope glycoprotein gp350/220 has bound to the CD21 cell receptor, which is also the receptor for the C3d component of complement [6]. During the lytic cycle, regulatory proteins belonging to the immediately early antigen (IEA) and early antigen (EA) groups are synthesized to allow the production of viral DNA(EBVDNA), the virion structural proteins (viral capsid antigen, VCA) and membrane proteins (MA). Serologic testing for immunoglobulin A (IgA) antibodies directed against EBV viral capsid antigen (VCA/IgA) has identified as a valuable method to screen individuals for NPC [7, 8]. Moreover, serologic testing for IgA/VCA and IgA antibodies to EBV early antigen (IgA/EA) has been used widely to screen for NPC in the areas of China in which it is endemic [9].

The IARC 2009 working group on carcinogenicity of biological agents found sufficient evidence to infer the causality of the role of EBV in Burkitt's lymphoma, NHL associated immunosuppression, NK lymphoma/extranodal T cells (nose type), Hodgkin's lymphoma, and NPC [10]. The role of EBV in the more general types of NHL and in immunocompetent individuals is still unclear, mainly because the prevalence of EBV in adults is $>90 \%$, and lifetime latent infections occur in the memory of B cells. The mechanism of HIV-1 is positive, individuals who experience immune deficiency have a higher risk for NHL. Decreased immune function can cause reactivation and replication of EBV. Reacting EBV itself can be a risk factor for NHL. Non-Hodgkin's lymphoma is a lymphocyte cell malignancy, associated with immune dysregulation, a decrease in immunity resulting in immune response and lytic reactivation of herpesviruses such as EBV in mucous tissue. Immune dysregulation occurs due to loss of immune control due to reactivation of the herpes virus and the production of infectious viral particles, which triggers the serum IgA profile to reactivate herpes viruses such as EBV [11]. Pathogenesis of Non-Hodgkin Lymphoma (NHL) Lymphomas are solid tumors of lymphocyte origin and are the most common hematopoietic cancers, representing most common cancer, in terms of incidence rate, and the sixth in terms of cancer deaths, in both men and women in the United States. 3 Lymphomas represent diverse and heterogeneous groups of cancers, consisting of Hodgkin lymphoma, T cell and natural killer cell lymphoma, and various types of B cell non-Hodgkin lymphoma $[7,8]$. Most types of B cell NHL correspond to B cells that have undergone various 
molecular changes that occur after an initial encounter with antigen and exposure to helper $\mathrm{T}$ cells [5] As these activation-promoting interactions occur in the germinal centers of lymph nodes and other lymphoid organs, these cells are referred to as post-germinal center B cells. The germinal center reaction involves rapid B cell proliferation and somatic DNA changes that result in both changes in the isotype of the Ig that is produced by these cells (from IgM to IgG or other isotypes), as well as enhanced antigen-binding affinity [9].

The standard method of diagnosis of EBV is Immunofluorescence Assay (IFA), but because this method is not practical, subjective and relatively expensive, a method of enzyme-linked immunosorbent assay (ELISA) is developed. The ELISA method has better sensitivity and specificity than IFA, is quantitative, objective, costs are relatively cheap, and is suitable for population detection on a large scale [12].

\section{MATERIAL AND METHODS}

This study is a comparative analytic observational study with crosssection design. The research subjects were patients diagnosed with NPC and NHL in Hasan Sadikin Hospital from June 2016 to July 2017 who were in accordance with inclusion and exclusion criteria and were willing to participate in the study and sign an informed consent.

Inclusion criteria: 1. WHO type III NPC patients from histopathological examination who have not undergone radiotherapy, chemotherapy, or combination therapy. 2. NHL patients from histopathological results who have not undergone chemotherapy. Exclusion criteria: 1. Patients with multiple carcinomas. 2. NPC and NHL residual/recurrent patients.

The sample selection technique used in this study is nonprobability sampling with consecutive sampling method. There are 16 samples each for NPC and NHL samples. Every NPC and NHL patients who come to the hospital who has not received treatment therapy, checks starting from the history (history of patient complaints, symptoms, duration, and onset of disease and previous history), then a general physical examination. Nasopharyngoscopy, biopsy and immunohistochemical examination, and investigations (hepatobiliary ultrasound, chest X-ray, nasopharyngeal CT scan) in accordance with the applicable standard operating procedure. The examination was carried out using the ELISA method to obtain IgA EA EBV levels found in both NPC and NHL patient.

\section{RESULT}

Table 1. Comparison of the Characteristics of the Two Groups of Research Subjects by Age

\begin{tabular}{|c|c|c|c|}
\hline \multirow[b]{2}{*}{ Variable } & \multicolumn{2}{|c|}{ Group } & \multirow[b]{2}{*}{$\mathbf{P}$} \\
\hline & $\begin{array}{l}\text { NHL } \\
n=16\end{array}$ & $\begin{array}{l}\text { NPC } \\
n=16\end{array}$ & \\
\hline Age & & & \\
\hline Mean \pm Std & $52.18 \pm 8.93$ & $46.81 \pm 16.42$ & 0.262 \\
\hline Median & 52.50 & 50.00 & \\
\hline Range (min-max) & $37.00-65.00$ & $18.00-74.00$ & \\
\hline
\end{tabular}

Decause the data are normally distributed. ** Signs indicate significant or statistically significant.

Table 2. Comparison of Characteristics of Both Study Subject Groups by Gender

\begin{tabular}{|c|c|c|c|}
\hline \multirow[b]{2}{*}{ Variable } & \multicolumn{2}{|c|}{ Group } & \multirow[b]{2}{*}{$\mathbf{P}$} \\
\hline & $\begin{array}{l}\text { NHL } \\
\mathrm{n}=16\end{array}$ & $\begin{array}{l}\text { NPC } \\
n=16\end{array}$ & \\
\hline Gender & & & 1.000 \\
\hline Man & $9(56.2 \%)$ & $9(56.2 \%)$ & \\
\hline Women & $7(43.8 \%)$ & $7(43.8 \%)$ & \\
\hline
\end{tabular}

In the table. 1 and table 2 of the NHL group found at an average age of $52.18 \pm 8.93$, male sex as many as 9 people or equal to $56.2 \%$, and female sex at 7 people or by $43.8 \%$. In the NPC group, the average age was $46.81 \pm 16.42$, male sex was 9 people or $56.2 \%$, and female sex was 7 people or $43.8 \%$.

Statistical tests to compare the average numerical data with two unpaired groups, the analysis carried out using the unpaired $\mathrm{T}$ analysis test because the data are normally distributed, namely the age variable. The results of the statistical test on the age variable obtained a p-value of 0.262 where the $p$-value is greater than $0.05(\mathrm{p}>0.05)$. So this shows not significant or not statistically significant. Thus it can be said that there is no difference in the average between age variables in the two study groups.

For analysis on categorical data, namely, gender tested using Chi-Square statistical test, obtained p-value of 1.00 where this p-value is greater than 0.05 (p $>0.05)$ which means it is not significant or not statistically significant. Thus it can be explained that there is no difference in the proportion of significant or statistically significant between the two study groups.

Based on the results of the characteristic analysis above, it can be concluded that in both groups there was no difference or the same or homogeneous. So that statistical tests can be carried out for further statistical hypothesis testing.

Table 3. Comparison of EA IgA antibody levels with the two research groups

\begin{tabular}{|c|c|c|c|}
\hline \multirow{2}{*}{ No } & \multicolumn{2}{|c|}{ Titer EA EBV IgA } & \multirow{2}{*}{$\mathbf{P}$} \\
\hline & NPC & NHL & \\
\hline & & & $0.0001 *$ \\
\hline 1 & 1.81 & 0.19 & \\
\hline 2 & 8.49 & 0.07 & \\
\hline 3 & 1.91 & 0.16 & \\
\hline 4 & 0.87 & 0.18 & \\
\hline 5 & 4.63 & 0.19 & \\
\hline 6 & 3.28 & 0.2 & \\
\hline 7 & 4.38 & 0.7 & \\
\hline 8 & 2.53 & 0.41 & \\
\hline 9 & 0.85 & 0.64 & \\
\hline 10 & 5.43 & 0.14 & \\
\hline 11 & 4.05 & 0.46 & \\
\hline 12 & 5.19 & 0.3 & \\
\hline 13 & 1.77 & 0.09 & \\
\hline 14 & 3.5 & 0.45 & \\
\hline 15 & 2.14 & 0.11 & \\
\hline 16 & 8.49 & 0.05 & \\
\hline Mean \pm Std & $3.71 \pm 2.36$ & $0.27 \pm 0.20$ & \\
\hline Median & 3.39 & 0.19 & \\
\hline Range (min-max) & $0.85-8.49$ & $0.05-0.70$ & \\
\hline
\end{tabular}

In the table. 3 describes the comparison of IgA EA in both groups. Statistical tests to compare the average numerical data with two unpaired groups, the analysis carried out to test this numerical data using the Mann Whitney analysis test because the data are not normally distributed, namely the numerical EA IgA variable. The results of the statistical test on the $\operatorname{IgA}$ EA variable obtained a value of $p$-value of 0.0001 where the p-value was smaller than $0.05 \quad(\mathrm{p}<0.05)$. This shows significant or statistically significant. Thus it can be said that there are differences in the mean between the IgA EA variables in the two study groups. In the NHL group, the IgA EA value of $0.27 \pm 0.20$ did not increase compared to the NPC group which had a higher average IgA EA than the NHL group which was $3.71 \pm 2.36$.

\section{DISCUSSION}

In this study, the results of statistical tests obtained on the age variable obtained $p$-value of 0.262 where the $p$-value is greater than $0.05(p>0.05)$. So this shows not significant or not statistically significant. Thus it can be said that there is no difference in the average between age variables in the two study groups. In this study, the highest age was obtained in patients with NPC and NHL in Hasan Sadikin Hospital between 40 to 50 years with an average age at NPC of $52.18 \pm 8.93$ and NHL at the age of $46.81 \pm 16.42$. This is in accordance with Adham $\mathrm{M}$ et al. Getting the most age of NPC patients at the age of 40-50 years as much as $32.4 \% 2$ and Cao SM et al in China getting the most age is decades 4-6 [3, 13]. Ahmadi A et al. in research at Kermanshah, Iran, found patients with non-Hodgkin's lymphoma associated with EBV aged $45 \pm 13$ years with a range of 28-73 years. Of the 12 patients $(60 \%)$ male and 8 patients (40\%) women [14].

The occurrence of NPC in the age range of 4-6 decades is caused by exposure to risk factors from the environment such as consumption of preserved and salted foods and exposure to carcinogenic substances that are long enough good so that it takes more time for the carcinogenesis process to occur $[1-3,6]$. Nasopharyngeal carcinoma increases in humans according to age. There are differences in age-related tumor distribution patterns in various organs and tissues. Aging can increase or decrease the susceptibility of various tissues to the initiation of carcinogenesis and usually facilitates the promotion and progression of carcinogenesis. Aging can predispose to cancer through several mechanisms, namely the accumulation of tissue from cells in the later stages of carcinogenesis, changes in homeostasis, specifically changes in the immune system and endocrine system, telomere instability related to aging and increased risk of cancer [15].

The prevalence of EBV in NHL in adults is $>90 \%$, and EBV establishes a lifetime of latent infection in the memory of $\mathrm{B}$ cells. Mechanisms Immunocompromised individuals have a higher risk for NHL due to immunosuppression which causes increased replication of EBV and other carcinogenic viruses. Decreased immune function can cause reactivation and 
replication of EBV. Psychological stress and aging can reduce the function of immune regulation and are involved in subclinical reactivation of EBV. Reactivation of EBV itself can be a risk factor for NHL. Besides, external factor agents responsible for reducing immune function can cause EBV reactivation and an increased risk of NHL [16].

Most sufferers of NPC and NHL are men. This result is in accordance with Sudrajat's research which states that there are 14 male NPC patients and 9 female patients with a ratio of 1.5:1.35 [17]. The same results were also mentioned by Cahyadi et al .'s study of male and female NPC patients with a ratio of 1.9:1.3 [18]. Madani et al. In 2015 mentioned patients with NPC in the Department of ORL-HNS Hasan Sadikin hospital in the period 2010-2014, which showed more male sufferers with a ratio of men to women 2-3:1 [19]. Xiao et al. Reported men are diagnosed with NPC more than women, with 213 people $(71.2 \%)$ and 86 people (28.8\%) respectively [20]. Tabyaoui et al., 2013 in Morocco getting a ratio between men and women is 2, 28:1. Boffetta, 2011, states that there are 356,000 new cases of NHL and 192,000 cases with mortality from NHL spread in 2008. Non-Hodgkin's malignum lymphoma or non-Hodgkin's lymphoma is a primary malignant lymphoid tissue. More than 45,000 patients are diagnosed as nonHodgkin's lymphoma (LNH) every year in the United States. Non-Hodgkin's lymphoma, especially central nervous system lymphoma is commonly found in patients with immune deficiencies and who get immunosuppressive drugs. NonHodgkin's Maligna lymphoma is the eighth-ranked malignancy found in men and ranks 11th in women. Countries with the highest incidence are in North America, Europe, Oceania and Africa. The incidence of NPC is more prevalent among men than women. This is because men are more exposed to environmental risk factors such as carcinogens, alcohol, and cigarette smoke. Also, exposure caused by work such as smoke, dust, steam, and chemicals as a risk factor for the occurrence of NPC is more common in men. In individual factors, there is a role for estrogen in women which has a protective effect against the progressive process of NPC, so there are fewer NPC patients in women than men $[1-3,15,19-22]$.

IgA EA levels in NPC were higher than NHL which was $3.71 \pm 2.36$. This is based on the semi-quantitative interpretation of the IgA EA ratio with ELISA, ie Interpretation: negative if the ratio is $<0.8$, borderline if the ratio $>=0.8-<1$, and positive if the ratio $>=1.1$

Sun, 2015, conducted a study in Shandong, China, found that there was an increase in serum IgA EA, IgA VCA and Sialic Acid (SA) in NPC patients. Immunoglobulin A VCA has a higher sensitivity $(76.19 \%)$ compared to IgA EA and SA, but IgA EA has a high specificity $(95.24 \%)$. This shows that EA is produced when EBV begins to replicate resulting in a high increase in specificity and low sensitivity. In Sun's study suggested a combination of examinations of IgA EA, VCA and SA IgA levels to obtain the right diagnosis and prognosis for NPC patients [13]. Shane et al. In their study found that there were serum IgA early lytic-antigen and Early Antigen-Diffuse (EA-D) in NHL sufferers. Earlylytic antigens are significant in viral replication DNA [14]. One possible alternative is to look for additional serological markers that detect by ELISA, such as EA that reflects two different patterns initially observed using immunofluorescence. About $70 \%-85 \%$ of patients with acute anti-EA EBV infection is positive antibodies up to three months after symptom onset. These high antibody titers during EBV reactivation and in NPC patients can also be found in $20 \%-30 \%$ of healthy subjects with a history of EBV infection $[10,13]$. Detection of anti-EA antibodies alone is not possible to identify each stage of the disease, but the combination with other parameters may be useful for making a laboratory diagnosis of acute EBV infection.

ELISA is the most sensitive semi-quantitative inspection method in detecting NPC. Positive serum numbers in NPC patients reach $100 \%$ via ELISA in a study. High sensitivity, fast sensitivity, enzyme-immunoassay is a handy tool for large-scale epidemiological studies for early diagnosis and monitoring of patients with nasopharyngeal carcinoma [20].

The Epstein Barr virus enters the human body and then replicates in epithelial cells and becomes latent in B lymphocytes. This viral infection occurs in two places, salivary gland epithelial cells, and lymphocyte cells. EBV begins to infect by binding to the $\mathrm{C} 3 \mathrm{~d}$ complement (CD21 or CR2). The mechanism of entry of EBV and the possibility of infection is possible by means of a direct connection between cells in the apical membrane with lymphocytes that have been infected with the virus. Besides that, it can be through the basolateral membrane, which is mediated by the interaction between integrins $\beta 1$ or $\alpha 5 \mathrm{~B} 1$ with EBV. Can also be through the spread of the virus directly through the lateral membrane that occurs after the first time infected with EBV. Viral infection in B lymphocytes is possible because of the bond between the glycoprotein gp350/220 membrane receptor on the EBV capsule and CD21 protein on the surface of B lymphocytes as the target. This process involves the interaction of several viral glycoprotein complexes including $\mathrm{gH}$ and $\mathrm{gL}$ which are homologous from the gp42 molecule with MHC class II in lymphocytes B. After binding to the $\mathrm{CD} 21$ receptor on lymphatic $\mathrm{B}, \mathrm{EBV}$ within 1-2 hours will enter the host cell cytoplasm then fusion occurs TR, which causes the epitope to be circular in shape, EBV particles will decompose and the EBV genomes will enter the nucleus, which is a form of latent EBV infection, which is characterized by process of cell activation and proliferation called EBV activation on $\mathrm{B}$ lymphocyte cells $[7,8,23,24]$.

Under normal conditions, EBV infection can be controlled and enter the latent phase, where only a few B cells are infected. The lytic phase can occur both in the epithelium of the oral cavity and in B cells which are located adjacent to the epithelium of the oral cavity, which causes many infectious EBV in the oral cavity so that it can spread to other people. In malignancies associated with EBV, the EBV genome appears in each tumor cell in the form of a latent epicome, and the genome will replicate during cell division. The expression of DNA in EBV in the form of latent episomal can be used as a basis in detecting viral function in the development of NPC [4].

The initial steps of EBV lytic infection are characterized by ZEBRA protein activity encoded by the BZLF1 gene found in epithelial cells and B lymphocytes. Several different products from genes that have correlations with lytic replication cycle stages can be identified and categorized into EMA, EA, VCA, LMA. In latent infections, expression of several proteins occurs: Epstein Barr Nucleus Antigen $2 \& 5$ (EBNA $2 \& 5$ ) which can be detected 2-5 hours after infection, Latent Membrane Protein $1 \& 2$ (LMP 1 \& 2) which can be detected 5-7 hours after infection. Latent infections that are silent and do not produce new viral particles are associated with one of them with NPC. The latent form of EBV infection in NPC includes type II with the expression characteristics of LMP proteins in addition to EBER and EBNA proteins [1, 10, 25, 26].

The exact mechanism by which EBV can induce cancer remains uncertain. However, further research on the expression of the LMP gene shows that it can alter nasopharyngeal epithelial cells in vitro, and it is estimated that LMP in cells infected with EBV protects these cells from a program of cell death or apoptosis. Whereas in other studies it was also found that the LMP gene was found in $65 \%$ of people with NPC [10].

The etiology of non-Hodgkin's lymphoma is oncogenes, EBV infections, Human T-leukemia Virus-I (HTLV-I), autoimmune diseases and immune deficiency. More than $90 \%$ of non-Hodgkin's lymphoma is Mature B-cell neoplasm. In North America and Europe, B-cell lymphoma is Follicular Lymphoma. Whereas, in Asia, 80-90\% form of diffuse lymphoma and T-cell lymphoma is more common. Lymphoma is differentiated based on cell type description of growth. Small cell types, intermediate and large cells, and the core form (cleaved and non-cleaved). In normal cell follicles polyclonal, whereas in monoclonal lymphoma cells with uniform morphological form and express the same immunoglobulin cells, namely light chain. Lymphoma originating from B cells can be identified with monoclonal antibodies that are specific to B-cells such as CD19, CD20, CD22, and CD79a. B lymphoma cells also have their immunophenotype component which requires multiparameter analysis. Small Bcell lymphoma consists of B-CLL/SLL (B-cell chronic lymphocytic leukemia/small lymphocytic lymphoma), LPL (Lymphoplasmacytic lymphoma), MCL (Mantle cell lymphoma), FL (Follicular lymphoma), MZL (nodal marginal zone B -cell lymphoma) identified with monoclonal antibodies CD5, CD10, CD23, CD43, slg, cytolg, bcl-1 and bcl-6. But not one antigen is specific to one type of lymphoma, so an antibody panel is needed. The type of B lymphoma is important for prognosis and treatment $[9,11,14,16]$.

In the WHO classification in 2008 , the age of the patient was considered as a feature of some newly entered disease entities. For example, in the FL category and nodal MZLs there are distinctive variants that are almost exclusively in the child's age group and are different from clinically and biologically mature. FL pediatric variants are usually local and high histological classes. This lymphoma lacks BCL2/IGH translocation and does not express BCL-2 protein. They may involve nodal or extranodal sites (testis, digestive tract, Waldeyer's ring). Pediatric FL has a good prognosis, with optimal management better results. The difficulty of diagnosis is a rare case of reactive follicular hyperplasia in children who have been reported to contain B-cell clonal CD10+germinal center populations but have not progressed to lymphoma. Nodal MZL in children seems to have a low risk of progression. Most patients present with stage I disease and have a low risk of relapse after conservative therapy [10]. In contrast, some diseases appear to occur most frequently in the elderly, such as EBV+DLBCL from parents, which may arise due to decreased surveillance of immunology. This lymphoma is clinically aggressive and is more common in extranodal than 
nodal sites. Neoplastic cells can resemble Hodgkin/Reed-Sternberg cells and show marked pleomorphism, with wider morphology than is usually seen in CHL. Necrosis and general inflammatory background. EBV+DLBCL parents must be distinguished from reactive hyperplasia associated with $\mathrm{EBV}$, which is also found in older people, who usually have benign results, most of which experience spontaneous regression [14, 27].

The antigen chosen for analysis represents a different phase of infection (ie primary, latent and reactive infection), and was chosen to increase the sensitivity of detection of EBV infection and potentially allow differentiation of the stages of infection. Immunoglobulin $\mathrm{G}$ (IgG) antibodies to viral capsid antigen (VCA) are produced within a few days of primary EBV infection and peak after $3-4$ weeks.

Furthermore, these antibodies decrease slowly but will remain throughout life. Antibodies for EBV nucleus antigen (EBNA) released in the subacute stage of the disease, and like VCA antibodies, persist indefinitely. BZLF1 encoded replicator activator (ZEBRA) is released during the lytic cycle in EBV permissive cells and antibodies are produced during primary EBV infection. ZEBRA is a key mediator of transition from latent to productive cycles on EBV and also as a virus reactivation marker. Antibodies to the initial antigen (EA) appear temporarily for up to 3 months during the acute phase of mononucleosis infection. During EBV reactivation due to immunosuppression, antibodies for EA increase quite high and persist in chronic infections [15, 23, 28, 29]. The limitation of this study is that it cannot determine the sensitivity and specificity of EA EBV IgA levels ELISA semiquantitatively because the results are divided according to positive, borderline, and negative values.

\section{CONCLUSION}

The EA EBV IgA antibody levels in WHO type III NPC were higher when compared to NHL. People with NPC and NHL are more likely to have male sex. The age of patients with NPC and NHL is highest in decades 4-6. NHL can give negative results on EA EBV IgA antibody examination and IgA EA cannot be used as early detection for NHL.

\section{REFERENCE}

[1] Li J, Lu T, Huang Y, Han F, Chen C, Xiao W. Clinical features of 337 patients with recurrent nasopharyngeal carcinoma. Chin J Cancer. 2010;29(1):82-6.

[2] Wei W, Chua D. Nasopharyngal cancer. Dalam Bailey BJ, Healey GB, Johnson JT, Rosen CA dkk, penyunting. Head and neck surgeryotolaryngology Philadelphia Lippincott Williams \& Wilkins Edisi ke-4. 1875;97.

[3] Adham M, Kurniawan AN, Muhtadi AI, Roezin A, Hermani B, Gondhowiardjo $\mathrm{S}$, et al. Nasopharyngeal carcinoma in Indonesia: epidemiology, incidence, signs, and symptoms at presentation. Chinese journal of cancer. 2012;31(4):185.

[4] Coghill AE, Hildesheim A. Epstein-Barr virus antibodies and the risk of associated malignancies: review of the literature. American journal of epidemiology. 2014;180(7):687-95.

[5] Young LS, Dawson CW. Epstein-Barr virus and nasopharyngeal carcinoma. Chinese journal of cancer. 2014;33(12):581.

[6] Sabirin MSM, Permana AD, Soeseno B. Epidemiologi Penderita Tumor Ganas Kepala Leher di Departemen Telinga Hidung Tenggorokan-Kepala Leher Rumah Sakit Dr. Hasan Sadikin Bandung, Indonesia, Periode 2010 2014. Tunas Medika Jurnal Kedokteran \& Kesehatan. 2016;3(1).

[7] Niedobitek G. Epstein-Barr virus infection in the pathogenesis of nasopharyngeal carcinoma. Molecular Pathology. 2000;53(5):248.

[8] Luo Y-L, Ou G-P, Chi P-D, Liang Y-N, Liu Y-H, Huang M-Y. Combined determination of Epstein-Barr virus-related antibodiesand antigens for diagnosis of nasopharyngeal carcinoma. Chinese Journal of Cancer. 2009;28(1):76-8.

[9] Boffetta P. I. Epidemiology of adult non-Hodgkin lymphoma. Annals of oncology. 2011;22(suppl 4):iv27-iv31.

[10] Bauer G. Simplicity through complexity: immunoblot with recombinan antigens as the new gold standard in Epstein-Barr virus serology. Clinical laboratory. 2001;47(5-6):223-30.

[11] Johnson ME, Robu VG, Turaka A. Nasopharyngeal Hodgkin lymphoma. Journal of Clinical Oncology. 2014;32(11):e40-e1

[12] Hess RD. Routine Epstein-Barr virus diagnostics from the laboratory perspective: still challenging after 35 years. Journal of clinical microbiology. 2004;42(8):3381-7.

[13] Cao S-M, Liu Z, Jia W-H, Huang Q-H, Liu Q, Guo X, et al. Fluctuations of epstein-barr virus serological antibodies and risk for nasopharyngeal carcinoma: a prospective screening study with a 20 -year follow-up. PloS one. 2011;6(4):e19100
[14] Shahriari-Ahmadi A, Izadi B, Sadeghi M, Payandeh M, Sadeghi E. Epstein-Barr virus and non-Hodgkin lymphoma: A study in Kermanshah, Iran. American Journal of Cancer. 2015;3(5):91-3.

[15] Paramita DK, Fachiroh J, Artama WT, van Benthem E, Haryana SM, Middeldorp JM. Native early antigen of Epstein-Barr virus, a promising antigen for diagnosis of nasopharyngeal carcinoma. Journal of medical virology. 2007;79(11):1710-21.

[16] Teras LR, Rollison DE, Pawlita M, Michel A, Brozy J, de Sanjose S, et al. Epstein $\square$ Barr virus and risk of non $\square$ Hodgkin lymphoma in the cancer prevention study $\square$ II and a meta $\square$ analysis of serologic studies. International journal of cancer. 2015;136(1):108-16.

[17] Henle W, Henle G. Epstein-Barr virus-specific serology in immunologically compromised individuals. AACR; 1981.

[18] Tabuchi K, Nakayama M, Nishimura B, Hayashi K, Hara A. Early detection of nasopharyngeal carcinoma. International journal of otolaryngology. 2011;2011.

[19] Anisimov VN. The relationship between aging and carcinogenesis: a critical appraisal. Critical reviews in oncology/hematology. 2003;45(3):277-304.

[20] D M. Karakteristik Karsinoma nasofaring di RSHS tahun 2010-2014. Biannual International Symposium on Nasopharyngeal Carcinoma Yogyakarta. 2015.

[21] Sixbey JW, Yao Q-Y. Immunoglobulin A-induced shift of Epstein-Barr virus tissue tropism. Science. 1992;255(5051):1578-80.

[22] Lequin RM. Enzyme immunoassay (EIA)/enzyme-linked immunosorbent assay (ELISA). Clinical chemistry. 2005;51(12):2415-8.

[23] Bhaduri-McIntosh S, Landry ML, Nikiforow S, Rotenberg M, El-Guindy A, Miller G. Serum IgA antibodies to Epstein-Barr virus (EBV) early lytic antigens are present in primary EBV infection. The Journal of infectious diseases. 2007;195(4):483-92.

[24] Banatvala JE, Pattison JR, Zuckerman AJ. Principles and practice of clinical virology: John Wiley \& Sons; 2000.

[25] Luderer R, Kok M, Niesters HG, Schuurman R, de Weerdt O, Thijsen SF. Real-time Epstein-Barr virus PCR for the diagnosis of primary EBV infections and EBV reactivation. Molecular Diagnosis. 2005;9(4):195-200.

[26] Fachiroh J, Prasetyanti P, Paramita D, Prasetyawati A, Anggrahini D, Haryana S, et al. Dried-blood sampling for epstein-barr virus immunoglobulin G (IgG) and IgA serology in nasopharyngeal carcinoma screening. Journal of clinical microbiology. 2008;46(4):1374-80.

[27] Vendrame E, Martinez-Maza O. Assessment of pre-diagnosis biomarkers of immune activation and inflammation: insights on the etiology of lymphoma. Journal of proteome research. 2010;10(1):113-9.

[28] Shan L, Yan D, Xi L, Chen Q-p, Liao X-c, Xue Q. Diagnostic value of Epstein-Barr virus capsid antigen-IgA in nasopharyngeal carcinoma: a meta-analysis. LWW; 2010.

[29] Tiwawech D, Chindavijak S, Saelee P, Sukarayodhin S, Ishida T, Ng PS Detection of IgA antibody against Epstein-Barr virus nuclear antigen 1 in nasopharyngeal carcinoma patients by ELISA. Thai Cancer Journal. 2008;28:83-92. 